\title{
Asoleado de Cauquenes y Concepción: apogeo y decadencia de un vino chileno con Denominación de Origen
}

\author{
"Asoleado" ("Sunny") of Cauquenes and Conception: The Rise and Fall \\ of a Chilean wine with Appelation of Origin
}

\author{
Pablo Lacoste ${ }^{1 *}$, Amalia Castro², Bibiana Rendón ${ }^{3}$, Philippo Pszczólkowski ${ }^{4}$, Natalia Soto ${ }^{2}$, \\ Michelle L. Adunka ${ }^{1}$, José Jeffs ${ }^{1}$, Alejandro Salas ${ }^{1}$, Carolina Cofrée ${ }^{1}$ Emiliano Núñez ${ }^{1}$
}

\section{RESUMEN}

El asoleado de Cauquenes y Concepción representa un caso de singular interés entre los vinos típicos de América Latina. En el siglo XIX era el mejor vino de Chile según las preferencias de los mercados. En la centuria posterior fue reconocido por el Estado en 1953 como el primer vino con Denominación de Origen del país, junto al pajarete y el vino licoroso del Elqui. Con estos antecedentes, el asoleado presentaba grandes perspectivas de desarrollo en los mercados nacionales e internacionales. Sin embargo, estas expectativas se vieron frustradas y el producto, en la actualidad, es irrelevante en la industria vitivinícola de Chile. El artículo examina el ciclo de auge del producto por medio de la prensa de la época (1850-1880), y aporta algunas explicaciones de su posterior declinación.

Palabras clave: asoleado, denominaciones de origen, vinos típicos, viticultura de Chile, industria vitivinícola.

\begin{abstract}
The "asoleado" (sunny) of Cauquenes and Concepcion represents a case of particular interest among the typical wines of Latinamerica. In the nineteenth century it was the best wine in Chile according to market preferences. In the following century, was recognized by the State in 1953 as the first wine with Appellation of Origin in the country, next to pajarete and sweet wine Elqui. With this background, sunny had high development prospects in domestic and international markets. However, these expectations were frustrated and product, at present, has no relevance in the Chilean wine industry. This article examines the boom cycle of the product through the press of the time (1850-1880), and provides some reasons for his subsequent decline.
\end{abstract}

Key words: sunny, designations of origin, typical wine, Chilean viticulture, wine industry.

\section{Introducción}

"Acaban de llegarme unas pocas cargas del legítimo mosto asoleado de Cauquenes, verdadero néctar por su sabor, pureza, color y salubridad que experimenta el que lo usa. Es licor que podría presentar con orgullo de regalo a Garibaldi”.

El Ferrocarril, 15 de setiembre de 1860

El Asoleado fue la primera Denominación de Origen (DO) de Chile. Fue delimitado por ley del Congreso en 1953, junto con el Pajarete del Huasco y el Elqui. Solo fueron precedidas por el Pisco (1931). Este último logró consolidarse con el tiempo, hasta convertirse en la principal DO de América del Sur y producto emblemático tanto de Chile como de Perú (Cortés, 2005; Huertas, 2012; Jiménez, 2014; Lacoste et al., 2013 y 2014). En cambio el asoleado no tuvo igual suerte y su presencia en el mercado es actualmente muy acotada. Por tanto, la historia del asoleado chileno es un caso interesante de DO fallida y conviene examinar su proceso de ascenso y declinación.

El estudio de los productos típicos y las DO representa una rama dinámica de las industrias

\footnotetext{
Universidad de Santiago de Chile, USACH . Santiago, Chile.

Universidad Nacional de Cuyo. Mendoza, Argentina.

Universidad de Chile. Santiago, Chile.

4 Pontificia Universidad Católica de Chile. Santiago, Chile.

* Autor por correspondencia: pablo.lacoste@usach.cl
}

Fecha de Recepción: 20 Febrero, 2015.

Fecha de Aceptación: 26 Agosto, 2015. 
agroalimentarias. Sobre todo porque al obtener estas jerarquías los productos del campo obtienen mejores precios de mercado, lo que mejora la rentabilidad de los campesinos. Ello implica un reconocimiento a su prolongado esfuerzo por elaborar productos de calidad superior y, a la vez, un sello de orgullo identitario. Las DO son parte del patrimonio de una nación, son como monumentos vitales, que contribuyen a mejorar la calidad de vida de los sectores rurales (Duhart, 2011). La academia ha respondido a estas inquietudes con la elaboración de una amplia literatura especializada en los últimos años (Coello, 2008; Buitrago, 2014). En el nuevo mundo vitivinícola en general, y particularmente en Chile, la corriente principal se ha inclinado a enfatizar los varietales antes que el terroir y las DO (Villanueva, 2014; Pszczolkowski, 2014 y 2015). De todos modos, el interés por las DO ha comenzado, poco a poco, a despertar (Álvarez, 2001; Errázuriz, 2010; Jeffs, 2014; Málaga, 2014). En este contexto, el presente artículo se focaliza en el caso del vino asoleado de Cauquenes y Concepción.

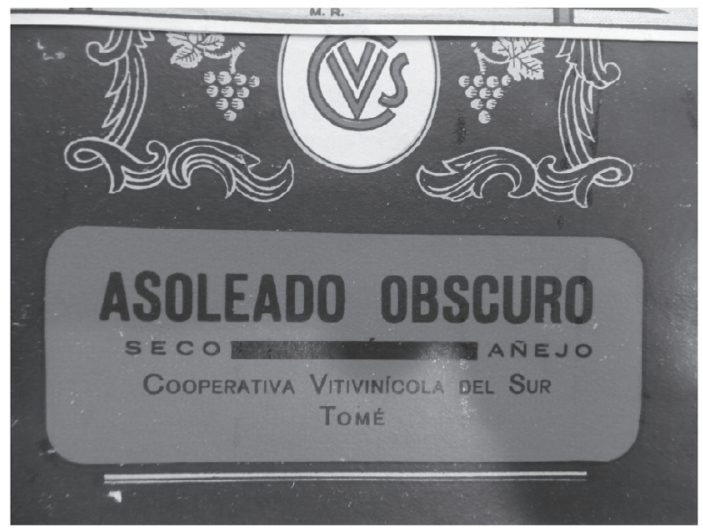

Figura 1. Etiqueta de vino Asoleado, registrada por la Cooperativa Vitivinícola del Sur, localizada en Tomé (30 km de Concepción) el 12 de junio de 1939. Fuente: Archivo del Instituto Nacional de Propiedad Industrial (INAPI). Registro 109251.

El vino asoleado se elabora a partir de uvas parcialmente deshidratadas al sol. Una vez maduros, los racimos son cortados y expuestos sobre las mismas parras, dos o tres semanas a la luz solar. Como resultado, el racimo se deshidrata y se produce mayor concentración relativa de azúcar en la uva. Cada cuatro o cinco días de asoleo, se incrementa $1^{\circ}$ de azúcar y se disminuye $10 \%$ el volumen de uva. Finalizado el proceso, se realiza la pisada de la uva y la fermentación, en la que la mayor presencia de azúcar genera un vino con alto grado alcohólico. Se obtiene así un vino licoroso. Respecto del vino común, el asoleado tiene mayores costos de producción y precios más altos (Gay, 1855; Rojas, 1891 y 1950).

Desde el punto de vista legal, este producto fue delimitado por primera vez en 1953 mediante la ley 11.256 (artículo 188), en la que se reivindicaron tres productos: el vino generoso del Huasco (Pajarete), el vino generoso del Elqui y el "vino generoso de Cauquenes" entre los ríos Maule e Itata. Esta norma se completó con el decreto 2.753 (1979) que delimitó la DO “asoleado" entre los ríos Mataquito y Biobío, abarcando todo el territorio entre Cauquenes y Concepción. A pesar del reconocimiento del Estado, el asoleado no logró consolidar sus posiciones y su presencia en el mercado ha tendido a desaparecer.

La decisión del Estado de delimitar el asoleado como DO refleja que este vino en su momento fue importante; sin embargo, por algún motivo perdió su relevancia. La literatura especializada en la historia vitivinícola de Chile apenas ha dedicado algunas menciones al asoleado (Gay, 1855; Pérez Rosales, 1886: 35; Le Feuvre, 1890; Del Pozo, 1999; Couyoumdjian, 2006). De estos autores, solo Gay, y en menor medida Le Feuvre, entregaron un desarrollo explicativo acerca de la naturaleza del asoleado; en cambio Pérez Rosales y Del Pozo apenas lo mencionan. La zona específica de producción del asoleado, entre Cauquenes y Concepción, también ha generado estudios relativos a la industria vitivinícola (Valladares, 1979; Sánchez Andaur, 2006; Mayorga, 2014; Soto, 2015; Stewart, 2015), con ello se demuestra la profundidad histórica de la viticultura en la región. Sin embargo, ninguno de estos trabajos detectó el asoleado como producto relevante en el período colonial. Quien lo detectó con claridad fue Claudio Gay: al realizar su relevamiento general de la agricultura chilena, el asoleado ya era visible (1855). Sin embargo, cuando décadas más tarde se comenzaron a escribir los primeros tratados de viticultura y vinificación (Rojas, 1891 y 1950), el asoleado ya había perdido vigencia. Por tanto, la revisión bibliográfica muestra que el ciclo histórico relevante del asoleado se desplegó precisamente entre Gay y Rojas, es decir, en la segunda mitad del siglo XIX.

El problema a abordar consiste, entonces, en describir y explicar el período crítico del asoleado, desde 1855 hasta 1891. Para avanzar en esa dirección se ha compulsado la prensa nacional de cuatro ciudades chilenas: Santiago (El Ferrocarril), 
Valparaíso (El Mercurio), La Serena (El Coquimbo) y Chillán (La Discusión). A partir de los avisos económicos y clasificados de estos periódicos se ha procurado conocer las principales características del vino asoleado, incluyendo envases, precios, puntos de venta, estrategias publicitarias y demás elementos que permitan comprender el ciclo histórico del vino asoleado de Cauquenes y Concepción.

\section{El asoleado y su origen geográfico: de Cauquenes a Concepción}

El asoleado se elaboraba en una zona marginal dentro de la industria vitivinícola tradicional de Chile, signada por pequeñas propiedades de producción principalmente artesanal. Así lo establecía la relativa pobreza de los terrenos, lo que marca una importante diferencia social con las zonas más ricas del país.

La región del Maule, incluyendo Cauquenes, era un territorio pobre y con limitado desarrollo económico en el siglo XVIII. Así lo señalaban recurrentemente sus autoridades, organizadas en el Cabildo de Talca. En 1764 "la mayor parte de los vecinos de este partido, se compone de sujetos pobres y miserables". ${ }^{1}$ Además, "las pulperías, tiendas, viñas y especies (son) cortas y de poco valor". ${ }^{2}$ En este marco de pobreza, el cabildo carecía de recursos para cumplir sus funciones más básicas, llegando en cierto momento a denunciar una "total carencia de medios". ${ }^{3}$ En este contexto, muchas veces fue necesario cancelar la celebración de fiestas cívicas y religiosas, tan típicas de las ciudades de América colonial. ${ }^{4}$ De hecho, en los primeros treinta años de vida de la villa de San Agustín de Talca, solo se había podido pasear el estandarte real "dos o tres veces." 5

La economía del Partido del Maule estaba centrada en la producción agropecuaria. La ganadería representaba dos tercios de la riqueza regional y tenía su centro en la cría de ganado ovino y actividades derivadas (tejidos de lana, cueros curtidos y quesos). Sobre esta base surgió el primer producto típico chileno: el queso de Chanco, este logró convertirse en el más famoso queso chileno en los siglos XVIII y XIX (Lacoste et al., 2014).

Después de la ganadería, la rama más dinámica de la economía maulina era el cultivo de la vid y la elaboración del vino. En este ámbito, la zona de Cauquenes representaba un espacio singular de la viticultura chilena tradicional. Una simple comparación con la zona núcleo permite contemplar las diferencias. En los alrededores de Santiago y en el valle del Maipo, en los siglos XVII y XVIII, se establecieron las haciendas más ricas, dentro de ellas surgieron las viñas más prósperas y con mejores instalaciones y equipamientos. La mayor disponibilidad de capital facilitó que en la zona central las viñas contaran con canales de riego, sistemas de sostén y conducción más elaborados (braseros y parrales). Las bodegas eran sólidas construcciones de dos plantas, techos de tejas y, a veces, con sótanos de conservación de los vinos. Los lagares eran muchas veces construcciones sólidas de piedra labrada o cal y ladrillo. A mediados del siglo XIX en la zona central ingresaron las cepas francesas, los agrónomos europeos y los nuevos métodos que tendían a modernizar la producción vitivinícola nacional, siguiendo los patrones de la viticultura francesa (Briones, 2006; Del Pozo, 2014).

Los viticultores de la región del Maule tenían un perfil muy diferente. Más pobres que sus primos de Santiago, carecían de capitales y medios equivalentes. En 1764 los cabildantes señalaban que "la más espléndida cosecha de sus vinos, aguardientes y otros efectos, aún en todo el partido, no exceden la cantidad de dos o tres mil arrobas". 6 Teniendo en cuenta la productividad estándar de la época (10 plantas por una arroba), ello implicaba que las viñas maulinas tenían apenas entre 20.000 y 30.000 plantas. Estas modestas cantidades contrastan con las grandes haciendas de la época, como las de los jesuitas: la Hacienda de Longaví (actual Linares) tenía 35.000 cepas (Valladares, 1977) y la Hacienda de Mendoza llegaba a 50.000.

Mientras en el centro se construían los canales de riego con las aguas del Maipo, en Cauquenes predominaban las viñas de rulo en el secano costero e interior. No había recursos para conducción mediante braseros ni de sostén por tutores: solo se cultivaban cepas de cabeza. Mientras en el Maipo una viña se tasaba a valor de 4 reales por planta, en Cauquenes solía valuarse a 1 real por cepa. Mientras en Santiago los lagares eran de cal y ladrillo, cuyo precio rondaba los \$150, en Cauquenes predominaban los lagares de cuero, que se conseguían a $\$ 5$. Pero estos modestos valores facilitaban, en Cauquenes, el acceso de los pequeños campesinos pobres a la industria vitivinícola (Lacoste, 2011; Mayorga, 2014; Soto, 2015).

Fue precisamente en esta zona sur, en el secano costero e interior, en Cauquenes, Itata y Concepción, donde los pequeños productores artesanales pusieron 
en marcha el vino asoleado. Ellos tenían dificultades para llegar con sus vinos a los mercados debido a las grandes distancias, los malos caminos, escasos puentes y los altos costos de flete. Con el asoleado encontraron la fórmula de disponer de un producto que, con menor volumen, tuviera un precio más alto, lo que tendía a disminuir la importancia relativa del costo del flete en el valor final del vino.

En el contexto del sistema de transportes tradicional que existía en Chile a fines del siglo XVIII y comienzos del XIX, el vino asoleado ofrecía una solución práctica que facilitaba el transporte y la distribución en los mercados de los grandes centros urbanos, principalmente Santiago.

Los pequeños viticultores de Cauquenes y zonas conexas pusieron en marcha este producto entre fines del siglo XVIII y comienzos del XIX. La propuesta fue aceptada por los mercados de Santiago y del resto de Chile. Los consumidores se manifestaron dispuestos a pagar un poco más por un vino dulzón de mayor calidad. El esfuerzo de los pequeños viticultores artesanales de Cauquenes y Concepción se vio reconocido y valorado por las élites chilenas, esto los animó a continuar con su esfuerzo. De esta forma se establecieron las bases para el surgimiento del asoleado como un producto típico del valle Central de Chile, particularmente del secano costero e interior del Maule Sur hasta Concepción, con centro en la localidad de Cauquenes. A mediados del siglo XIX, cuando el gobierno de Chile encargó a Claudio Gay realizar el relevamiento de la producción agrícola, el asoleado estaba en pleno desarrollo. En su señera obra, Gay dedicó una página al vino asoleado de Chile. Se trata de un párrafo central, porque durante un siglo y medio ha sido la descripción más completa que se ha elaborado acerca del asoleado. Por este motivo, conviene transcribirla en forma completa:

\footnotetext{
"Mosto asoleado: este mosto, que se prepara también en la provincia de Concepción y en algunas otras provincias, se hace, como muchos de los de Hungría etc., con uvas expuestas a 15 o 20 días al sol antes de ser pisadas. Su bondad se debe, en cierto modo, según que han sido más o menos asoleadas. Las que han permanecido 25 días producen un vino mejor que las que solo han estado 20 o 15 días, exceptuando las circunstancias especiales de calidad. La uva por este procedimiento se echa en
}

una tina después de haberla prensado con las manos, y se la deja fermentar durante ocho o nueve días al cabo de los cuales se la saca de la tina para traspasar el líquido a las tinajas". Más adelante compara el asoleado con otros vinos chilenos, y de aquél afirma que se vende "a un precio siempre más caro". Y luego detalla que "los mejores son los de las haciendas de los Mauelas, de las Palmas, de los Maytenes del Rosal, de Rauquil, Cayumahue, etc, y gozan de gran favor en todo Chile y en la costa. En general los de la provincia de Nuble son inferiores en bondad a los de las provincias de Maule y de Concepción. Sin embargo los de Quinchamalí, Huechupin, etc., también tienen buena fama" (Gay, 1973).

Este texto de Claudio Gay relativo al asoleado es una página clásica de la historia del vino chileno. En los años siguientes, poco se pudo añadir a esos conceptos. Así, por ejemplo el agrónomo francés René Le Feuvre hizo una modesta contribución. Al referirse a los vinos maulinos, el autor señalaba: "Dos clases de vinos se producen en esta región; vinos secos y vinos dulces. Los primeros se obtienen con la uva recién cosechada; para fabricar los segundos se hace asolear la uva durante algunos días sobre el suelo y sobre las mismas parras" (Le Feuvre, 1890).

La producción del Fundo Quilquilmo fue un caso representativo de este proceso. Era una propiedad de 367 hectáreas, ubicada en el $3^{\text {er }}$ distrito de Caliboro, en la $11^{\circ}$ delegación de El Carrizal, del departamento de Cauquenes. Allí se cultivaba una pequeña viña y se elaboraba el vino asoleado. El 12 de setiembre de 1865 sus propietarios José Ramón Rodríguez, José Ramón Villalobos y María del Carmen Vivanco comprometieron la venta de 200 @ de vino asoleado de buena calidad a don Fidel Montero, comerciante de la plaza de Cauquenes. Fue una venta adelantada de la siguiente cosecha: el vino se entregaría el 15 de mayo del año siguiente. Muy interesante fue el precio pactado: $\$ 2,25$ por arroba. En total, la operación se realizó por $\$ 450$ que el comerciante pagó por adelantado. Como garantía, los tres viticultores cedieron la hipoteca por el fundo, lo que implica que el mismo era un terreno pobre (se valuaba a $\$ 1,22$ por hectárea). Paralelamente, resulta notable el alto precio estimado por el vino asoleado, ello destaca el prestigio de este producto. ${ }^{7}$ 
Poco a poco los viticultores del valle Central, particularmente del Maule Sur, fueron consolidando la tradición de elaborar los vinos asoleados. La práctica de prolongar la acción solar sobre la uva se hizo costumbre para obtener vinos escogidos. El mercado valoró el esfuerzo de los viticultores por ofrecer un producto distinto. El diálogo entre viticultores y consumidores terminó por legitimar un vino típico del sur del valle Central de Chile.

\section{La expansión del comercio chileno 1850-1880}

La segunda mitad del siglo XIX fue un período de grandes transformaciones para la economía chilena. El país ingresó en un ciclo de crecimiento económico, con el consiguiente aumento de la población y la capacidad de consumo. La población chilena subió de 1 millón en 1830 a 1,5 millones en 1854 y 2,7 en 1895 . Las zonas urbanas fueron protagonistas de este proceso, con la migración del campo a la ciudad. En pocos años las antiguas aldeas coloniales se convirtieron en prósperas urbes. Entre 1864 y 1895 Valparaíso pasó de 52.000 habitantes a 104.000 y Santiago de 115.000 a 256.000. A ello se sumaban otras capitales del norte y del sur que, aquel año (1895), ya alcanzaban números considerables como La Serena (15.000), Talca (33.000), Chillán (34.000) y Concepción (40.000).

El aumento del nivel de actividad económica facilitó, paralelamente, el incremento de los ingresos fiscales, la expansión del Estado y sus servicios públicos, mediante la expansión de la burocracia. Las ciudades chilenas observaron el ascenso de una incipiente clase media de funcionarios públicos que prestaban servicios de educación, salud, seguridad, justicia y obras públicas. A ellos se sumaron los empleados de los emergentes servicios de transportes y comunicaciones, entre otras actividades que se hallaban en plena expansión.

En efecto, en la segunda mitad del siglo XIX Chile se incorporó a la segunda revolución industrial, con la rápida expansión de los nuevos sistemas de transportes y comunicaciones. La navegación a vapor, los ferrocarriles y telégrafos establecieron lazos cada vez más estrechos entre las ciudades y el campo, facilitando de esta manera el flujo de productos agroindustriales a los centros de consumo.

El comercio exterior chileno (importaciones y exportaciones) experimentó también una edad dorada en este período, alentado por actores nacionales e internacionales. Las exportaciones de productos primarios chilenos generaban divisas suficientes para financiar la creciente demanda de bienes importados. Valparaíso se convirtió en uno de los más dinámicos puertos del Pacífico Sur Americano, llegando en algunos momentos incluso a superar la dinámica de El Callao. En 1830 ingresaron a Valparaíso 500 barcos y operaban en el puerto 48 casas comerciales (Contreras y Cavieres, 2005: 196). En los años siguientes, estas cifras se incrementaron velozmente. Un papel central en este proceso cupo a los comerciantes británicos, que aportaron una dinámica sin precedentes en el comercio mayorista y minorista de Chile.

Poco a poco, la sociedad observaba, con asombro, la gran transformación comercial: se desvanecían las pautas austeras y de subsistencia del período colonial, para dar paso a la economía de mercado, signada por el aumento de la escala de la producción, los transportes rápidos y baratos, y la promoción del consumo por los medios masivos de comunicación (prensa escrita principalmente). Dentro de este sistema se produjo la expansión del vino asoleado que llegaba principalmente de Concepción y Cauquenes.

Había también otros factores que condicionaban el desarrollo de los productos agroalimentarios chilenos con identificación geográfica y estándares de calidad más altos que el común. Por un lado, las élites chilenas, como en el resto de América Latina, tendían a sobrevalorar los productos europeos respecto de los locales. Por razones de estatus, modas y necesidad de diferenciarse del consumo popular, las élites latinoamericanas tendían a interesarse por los productos importados, incluyendo alimentos y bebidas provenientes de Francia, Italia, España, Portugal y el Reino Unido, entre otros. Bebidas importadas eran muy valoradas como el champagne, oporto o jerez, lo mismo que los quesos de Brie, Cheddar y Neufchatel. En el marco del paradigma del libre cambio, las élites chilenas eran partidarias de bajar los aranceles de importación y facilitar la llegada de estos productos al mercado nacional. Todo ello tendía a inhibir el desarrollo de los productos típicos nacionales de alta calidad, pues solo las élites podían pagar sus altos costos.

De todos modos en Chile existía un cierto freno para esta tendencia, debido a las restricciones fiscales. Los modestos ingresos del tesoro nacional imponían límites a la tendencia ideológica al descenso de las barreras arancelarias. En efecto, 
las dos principales fuentes de recursos fiscales eran los impuestos de exportaciones de cobre, y los aranceles de importación, llamados "impuestos de entrada". Por ejemplo la Ordenanza de 1851 estableció una tasa del 25\% para la importación de la mayor parte de los productos. Estas barreras bajaron al 15\% en 1864 y volvieron a subir en 1872 . El objetivo no era alentar una política proteccionista, sino asegurar el equilibrio fiscal. "Lo importante era mantener el nivel de ingresos provenientes de los impuestos de internación. Hasta 1870 ellos siguieron siendo individualmente la partida más importante de los haberes fiscales y sus valores fueron aumentando progresivamente (Contreras y Cavieres, 2005 p. 206).

En la relativa pobreza de Chile estaba justamente su fortaleza. Al no disponer de la renta fácil de bienes exportables en abundancia, la economía chilena tendía a generar un ambiente propicio para el desarrollo de productos con mayor valor agregado, como las bebidas y alimentos típicos, cuyos ejemplos más notables fueron el vino asoleado de Cauquenes y Concepción, y el queso de Chanco. Nótese que estos productos surgieron, justamente, del secano interior de la zona sur del valle Central, zonas de modestos recursos donde el actor social clave era el pequeño campesino pobre, cuyos recursos se encontraban principalmente en la cultura del trabajo.

\section{Hacia la construcción del mercado}

El vino asoleado fue promovido por los medios masivos de comunicación de la época, particularmente la prensa escrita. Los diarios y periódicos cumplieron un papel crucial en la expansión de la actividad comercial de buena parte de los países de Europa y América entre mediados del siglo XIX y la década de 1930. Después de esa fecha, la expansión de la radiofonía abrió una nueva etapa en la historia de los medios de comunicación. Pero hasta entonces la prensa gráfica ejerció un papel central. Los periódicos de las grandes capitales y ciudades menores brindaban creciente espacio a los avisos comerciales y económicos. Mediante estos espacios, se promocionaban los productos nacionales e importados, que debían competir por los consumidores. En este proceso tomó parte el asoleado.

En las décadas de 1850, 60, 70 y 80, el mosto asoleado experimentó una expansión notable gracias a los avisos comerciales dedicados a la promoción y venta de bebidas alcohólicas en Chile. A lo largo de todo este período el asoleado de Cauquenes libró una intensa competencia con otras bebidas nacionales (vinos, chichas) y extranjeras (vinos y aguardientes de España, Francia y Portugal). Los comerciantes libraron grandes batallas comerciales en torno a estos productos, ello generó un interesante y rico corpus documental para conocer la historia.

El comercio estaba en una etapa de transición, a mitad de camino entre la venta ambulante y los negocios formalmente establecidos. Con frecuencia, los productos en general, y el vino asoleado en particular, se promovían en la prensa para ser vendidos en lugares improvisados o transitorios tanto en Santiago como en Valparaíso. Lo importante no era el prestigio del vendedor ni de su casa de comercio, sino el producto mismo. En 1872 se ofreció una partida de asoleado de Cauquenes en una herrería de la plaza del Orden en Valparaíso $(E l$ Mercurio, 3 de agosto de 1872). En otra ocasión se promovió una pequeña cantidad de vinos de Cauquenes en venta en una habitación del Hotel Lafayette (El Mercurio, 21 de julio de 1879). En otros casos, el punto de venta quedaba librado al interés del cliente: este podía elegir si deseaba adquirirlo en el puerto de Constitución o en el de Valparaíso (El Mercurio, 22 de marzo de 1877). A veces, el comerciante eventual arrendaba una bodega para vender allí sus productos. No era una casa de comercio de carácter permanente y especializado, sino un lugar de tránsito, solo para depositar los vinos hasta la venta. Por ejemplo en Santiago, el asoleado de Cauquenes se vendía en la bodega de calle Santa Rosa 59. Además, en la calle San Francisco se vendía en dos locales (ubicados en los números 66 y 94. También se podía comprar el asoleado en calle Nevería (junto al convento de Santo Domingo), En Valparaíso, el asoleado se comercializaba en una bodega ubicada en la calle del Teatro 78. El tiempo del arriendo era acotado y si el comerciante no alcanzaba a vender sus existencias antes de su vencimiento, debía rematar el stock. Ello motivó también la publicación de avisos específicos.

En este movedizo escenario, pronto surgieron comerciantes que vieron en el asoleado una oportunidad de abrir un negocio permanente especializado en vinos de alta calidad. Así lo entendió Carlos Betancur quien abrió su negocio en calle Blanco $\mathrm{N}^{\circ} 58$, junto al Hotel Colón, y se reivindicó como el pionero en ofrecer estos productos: 
"Teniendo presente que no existe en Valparaíso un depósito en que se vendan vinos de primera clase, por mayor y menor, he resuelto abrir al público una gran bodega, en donde encontrarán los aficionados los más puros y mejores vinos que se introducen en esta plaza y que me llegarán por cada vapor del sur: mostos secos y asoleados, y vinos tintos y blancos de varias clases, los que venderá a precios sin competencia" (El Mercurio, 30-9-1873).

De a poco se comenzaron a consolidar las casas de comercio permanentes que apuntaban a proyectos de largo plazo dentro del rubro de la venta de alimentos y bebidas, entre estos se brindaba un espacio considerable al vino asoleado. El impulso inicial era poner en marcha un emprendimiento con el nombre del comerciante que se hacía responsable de la calidad de sus productos. Se comprometía el buen nombre y honor del vendedor como garantía, para construir el lazo de confianza con el consumidor. Con esta metodología se abrieron numerosos puntos de venta estables para comercializar el asoleado de Cauquenes y Concepción. Un exponente de este criterio en Valparaíso fue H. Maupas, que promovía mostos de Concepción y Cauquenes (El Mercurio, 6-6-1870; 16-5-1870; 1-6-1874). Durante cuatro años este importante comerciante de Valparaíso se apoyó en el asoleado de Cauquenes como producto emblemático para consolidar su negocio.

El asoleado fue también pilar del comercio de bebidas en Santiago. Agustín Fragua ofrecía asoleado en su tienda de calle Huérfanos 27 A; Pedro Silva lo hacía en calle 18 esquina Alameda; cerca de allí estaba la tienda de Juan Echeverría (Las Delicias 185). O bien en el negocio de Camilo

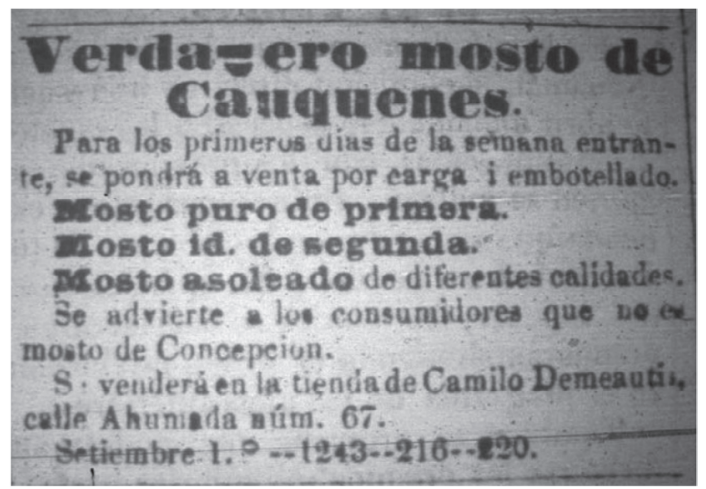

Figura 2. El Ferrocarril, 25 de agosto de 1856.
Demeautis (Alameda 67). Por su parte, R. Macaya lo vendía en su tienda de Catedral 135. En Chillán, Manuel Quiroga vendía mosto de Concepción de superior calidad, ofertando asoleado tinto dulce a 20 cts. la botella, asoleado blanco dulce a $20 \mathrm{cts}$. la botella, seco tinto a $10 \mathrm{cts}$. la botella (La Discusión, noviembre de 1874).

El paso siguiente fue el surgimiento de casas de comercio con nombre impersonal. Lo importante ya no era el nombre propio del vendedor sino la marca abstracta de la firma. En Santiago, los puntos de venta más glamorosos eran el "Almacén Francés" (calle Chirimoyo 18-C) y el "Almacén de vinos y licores" de H. Franzoy e Hijo, ubicado en el Portal Mac Clure, en la calle Monjitas. También surgieron negocios con marcado sentido identitario, como "La Damajuana Tricolor", colorido negocio de bebidas y productos del país (chichas y vinos), situado en la esquina de calle 21 de Mayo $\mathrm{N}^{\text {os }} 6$ y 8 . Mientras tanto, en la plaza de la Merced de Chillán en "El Arca de Noé", se ofrecían "acreditados vinos añejos, secos y asoleados; una especialidad en aguardientes con anís y sin él, los que ofrezco en venta desde una botella hasta tres mil arrobas" (La Discusión, diciembre de 1875). En La Serena, el vino asoleado se vendía en la "Bodega de Licores" que Calixto Gallardo abrió en la calle Colón 91 (El Coquimbo, 31-12-1891).

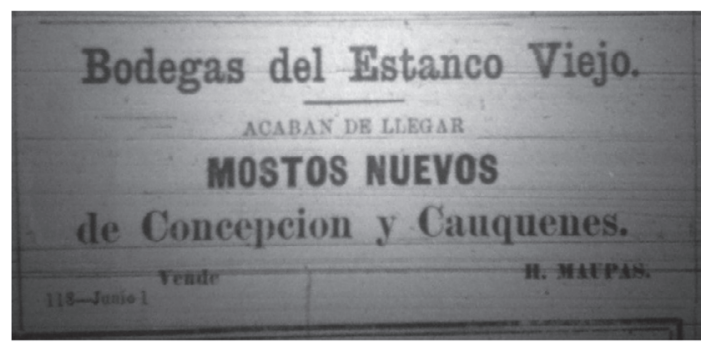

Figura 3. El Mercurio, 1 de junio de 1874.

Por lo general, el vino asoleado de Cauquenes se vendía en tiendas de bebidas alcohólicas, compitiendo con otros productos nacionales y extranjeros. En Santiago, en el Portal Mac Clure, el asoleado se presentaba junto a vinos franceses como Chateaux Margaux o Chateau Laffite (El Ferrocarril, 19-8-1879; 7-11-1879) o bien con otros productos importados como cognac, oporto y priorato $(E l$ Ferrocarril, 23-1-1878). En el Almacén Francés, el asoleado se ofrecía junto a otros vinos, licores y alimentos importados de Europa (El Ferrocarril, 15-9-1896). En otros comercios, el asoleado de 
Cauquenes debía competir con productos nacionales: vinos y chichas, aguardientes y piscos. Esta situación se daba también en La Serena (El Coquimbo, 31-121891) y sobre todo en Valparaíso donde H. Maupas, en "la Bodega del Estanco Viejo", vendía productos importados (sobre todo cognac) junto con los licores de su propia fábrica, y los mostos de Cauquenes y Concepción (El Mercurio, 6-6-1870; 16-5-1870).

Resulta notable el paralelismo del ciclo de crecimiento del asoleado y del comercio de bebidas y productos alimentarios en Chile en el tercer cuarto del siglo XIX. Fueron como dos caras de la misma moneda, procesos simultáneos y complementarios. La historia del asoleado quedó íntimamente ligada a la historia del comercio; fueron como hermanos de una misma familia que daban juntos sus primeros pasos, apoyándose mutuamente, el uno en el otro.

El vino asoleado se distribuía en distintos envases, principalmente botellas o barricas. En el almacén de H. Franzoy e Hijo el asoleado se vendía en botellas (El Ferrocarril, 23-1-1878), o bien en cajones de botellas. En otros comercios de despachaba en barricas de roble de seis arrobas (cerca de 220 litros) o bien barrilitos de dos arrobas (70 litros). Esta modalidad se promocionó tanto en Santiago como en Valparaíso, donde se ofrecía una partida de 74 barriles de dos arrobas de asoleado de Cauquenes (El Mercurio, 13-4-1872). El vino asoleado de la Hacienda San Nicolás de Longaví también se despachaba en barriles pequeños de 80 litros (El Mercurio, 27 de enero de 1872).

El asoleado era el vino chileno más valorado por el mercado y, por tanto, tenía los mejores precios. Hacia mediados de la década de 1870 el vino asoleado se tasaba a $\$ 8$ por arroba el de calidad superior y a $\$ 6$ el de calidad inferior. Le seguían en valor el vino blanco moscatel (\$5), el vino blanco ordinario $(\$ 2,50)$, el vino seco superior (\$3), el seco inferior $(\$ 2,30)$. Entre las marcas que competían por el mercado del vino asoleado se encontraban Paulsen y Barrera (El Ferrocarril, 11-3-1875). Un lustro más tarde, el liderazgo del asoleado se mantenía intacto. El mosto asoleado de Cauquenes seguía cotizado a $\$ 8$ por arroba, mientras que los vinos secos se vendían a $\$ 3,50$ por arroba (El Ferrocarril, Santiago, 6-12-1880). Dos años más tarde, una nueva lista de precios mostraba que se mantenía la hegemonía del vino asoleado: en "La Damajuana Tricolor" la arroba de asoleado se vendía a $\$ 6, \$ 8$ o \$10, claramente a mayor precio que otros vinos y chichas (la chicha común valía $\$ 3,50$ a $\$ 4$ y la chicha especial entre $\$ 5$ y \$ 6) (El Ferrocarril, 17-6-1882).

La competencia entre las distintas casas de comercio generó el desarrollo de distintas estrategias para atraer a los clientes. Y uno de los puntos críticos era la calidad y el origen geográfico de los productos. Así se pudo ver, por ejemplo, en el diario El Ferrocarril (Santiago de Chile), en la edición del 25 de agosto de 1856. El anuncio llevaba un título sugerente: "Verdadero mosto de Cauquenes". Y se trataba de diferencias de otras regiones geográficas: "se advierte a los consumidores que no es mosto de Concepción", señalaba el aviso. Con el correr de los años, la competencia dio lugar a avisos cada vez más ingeniosos, llegando a articular el humor y la creatividad. Un buen ejemplo fue el aviso publicado por Pedro Silva Barceló en El Ferrocarril (15 de setiembre de 1860):

"El que no lea se va de este mundo al otro sin saber lo que es canela".

Acaban de llegarme unas pocas cargas del legítimo mosto asoleado de Cauquenes, verdadero néctar por su sabor, pureza, color y salubridad que experimenta el que lo usa. Es licor que podría presentar con orgullo de regalo a Garibaldi.

En Santiago muy raras personas tendrá de él conocimiento por la dificultad de conseguirlo".

Este aviso representa una síntesis de los argumentos que se empleaban para llamar la atención del producto y destacar sus cualidades. Por un lado, se destaca el origen geográfico genuino del producto: se trata del auténtico "asoleado de Cauquenes", fórmula que asociaba dos conceptos contundentes. El público sabía que el asoleado era un vino de alta gama; y dentro de sus variantes, el mejor era, precisamente, el asoleado de Cauquenes. El aviso insiste en su carácter exclusivo y la dificultad que existía para conseguirlo.

La reivindicación del origen del asoleado tenía distintos grados de definición. Por lo general se mencionaba una localidad amplia: Cauquenes o Concepción. Pero también se impulsaron lugares más específicos. Dentro de Cauquenes se promovió como un asoleado de singular valor el que se elaboraba en Chonchos. ${ }^{8}$ En otra oportunidad se destacó un vino asoleado de Cauquenes proveniente del Fundo Bellavista. ${ }^{9}$ También se sumó a la corriente de 
elaborar vino asoleado la Hacienda de Longavíi. ${ }^{10}$ Es importante señalar que, originalmente, esta propiedad no había tenido necesidad de elaborar productos tan elaborados, pues contaba con envergadura económica suficiente para operar sin grandes complicaciones: basta recordar que en la segunda mitad del siglo XVIII ella sola poseía más cepas de vid que todos los pequeños productores del partido del Maule. Pero posteriormente, ante el éxito alcanzado por el vino asoleado, los administradores de esta hacienda resolvieron sumarse a la tendencia y realizar sus propios vinos con estas técnicas.

La asociación con grandes figuras mundiales fue otro recurso para construir la imagen del asoleado de Cauquenes. Así como en la actualidad las grandes marcas contratan figuras del deporte, la moda y el cine, los diseñadores de la publicidad del asoleado apelaron a figuras del mundo político internacional. Un caso emblemático fue la evocación de Giusepe Garibaldi quien había alcanzado estatura mítica, tanto en América como en Europa (Dumas, 2005; Troyat, 2006). Reconocido por los servicios prestados en Uruguay y Argentina, Garibaldi orientó sus esfuerzos después hacia la unidad italiana, cuyo principal obstáculo era el rey de Nápoles. La campaña patriótica de Garibaldi culminó con su ingreso triunfal en esa ciudad, los primeros días de setiembre de 1860. Garibaldi emergió entonces como la figura del momento. Una semana después, en Santiago de Chile, se publicaba el aviso que valoraba al asoleado de Cauquenes, el vino más

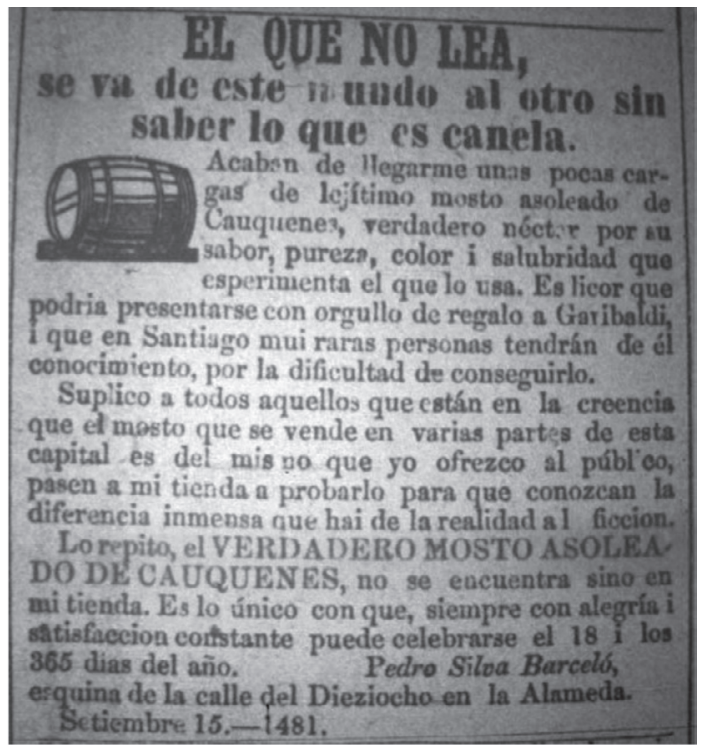

Figura 4. El Ferrocarril, 15 de setiembre de 1860. prestigioso de la viticultura chilena de entonces, como un regalo digno de Garibaldi.

Otro camino para fortalecer comercialmente al vino asoleado fue el desarrollo de las marcas. Uno de los antecedentes más interesantes fue el surgimiento de la marca Galpón, a comienzos de la década de 1880. Fue el plan de Julio Chaigneau con su almacén de bebidas y alimentos importados. Su aviso señalaba: "Vinos del sur, secos, asoleados y de la afamada marca "Galpón" se encarga de hacer venir" (El Mercurio, 23 de marzo de 1881). Esta fue una de las primeras marcas de un vino chileno, y sirvió para abrir el camino de las tendencias que se iban a desarrollar más tarde.

\section{Decadencia del asoleado después de la guerra del Pacífico}

El ciclo 1850-1880 marcó el ascenso del vino asoleado de Cauquenes y Concepción. Como se ha examinado, en esta etapa, este vino logró ingresar en los marcados de Santiago y Valparaíso, donde fue reconocido como el mejor vino chileno. Era el producto emblemático de la industria vitivinícola nacional. En términos actuales, el asoleado era el "tope de gama" de los vinos chilenos. En la escala de precios, se hallaba en la cima.

Con un producto de buena calidad, con prestigio asociado a su origen geográfico, y con el reconocimiento del mercado por su precio, el asoleado de Cauquenes no solo era un sólido vino típico del valle Central, sino que también se encontraba en condiciones de consolidarse como el primer vino chileno con Denominación de Origen. Había logrado cumplir con las distintas etapas que normalmente se requieren para alcanzar este nivel de prestigio y reconocimiento. Solo le faltaba el perfeccionamiento jurídico mediante la delimitación respectiva y el respaldo del Estado para garantizar su desarrollo.

Todas las expectativas se vieron frustradas después de la guerra del Pacífico. La presencia de este producto en los medios de comunicación comenzó a debilitarse. Los avisos comerciales promoviendo el asoleado se hacían cada vez más pequeños y esporádicos. Las casas de licores, bebidas y alimentos, que antes utilizaban el asoleado como título principal de sus anuncios con letreros grandes, comenzaron a colocarlo en un lugar secundario, con letras pequeñas, hasta finalmente suprimirlo. 
Paradójicamente, las casas comerciales que el asoleado, con su prestigio, contribuyó a levantar e instalar en el mercado chileno, una vez consolidadas, abandonaron a su suerte al otrora rey de los vinos nacionales. En su lugar se focalizaron en productos importados como champagne, jerez, oporto y cognac. En la década de 1890 se hizo cada vez más difícil encontrar avisos económicos, comerciales y clasificados relativos al asoleado.

El cambio de estrategia de los comerciantes fue en parte causa pero sobre todo consecuencia del cambio de los hábitos de consumo. Las élites chilenas experimentaron un giro en sus tendencias, al abandonar el hasta entonces mejor vino de Chile, y reemplazarlo por los productos importados de Europa. Este cambio fue parte de un proceso mayor, signado por la tendencia general de los países latinoamericanos de admiración por la cultura Europea, lo que fue parte del ambiente cultural de toda la segunda mitad del siglo XIX. En el caso chileno, estas tendencias se vieron moderadas durante varias décadas por las necesidades de austeridad del erario público. Ello servía para mantener altas las tarifas aduaneras para productos importados y aseguraba cierta moderación en los hábitos de consumo, a la vez que aseguraba cierto proteccionismo de infancia a los productos típicos de la industria agroalimentaria chilena, como el queso de Chanco y el vino asoleado. Pero la guerra del Pacífico significó un cambio radical en esta situación.

La anexión de los territorios conquistados por la guerra generó nuevas fuentes de financiamiento para el físco chileno. Este dejó de depender de los impuestos de importación, pues los ingresos del salitre representaron un aporte sin precedentes para las arcas públicas. Como resultado, los partidarios del libre cambio ya no tuvieron obstáculos fiscales para bajar las barreras arancelarias y las importaciones se hicieron cada vez más fáciles. En consecuencia, después de la guerra del Pacífico se registró un sensible aumento de las importaciones de vinos blancos embotellados de Europa (champagne, jerez, oporto) (Couyoumdjian, 2006).

Las rentas salitreras generaron en Chile un impacto sin precedentes de frivolidad, ostentación y colonialismo consumista, integrando a sus élites con las de otros países latinoamericanos en circunstancias similares. En otras regiones latinoamericanas la cultura de la renta emergió como consecuencia de la economía de plantación (azúcar, algodón, café, tabaco, caucho); sobre todo en las zonas tropicales del Caribe, y el norte de América del Sur, surgieron estos modelos basados en grandes latifundios controlados por un reducido número de personas. Estos modelos generaron sociedades segmentadas, que se decantaron en prácticas de singular frivolidad. Las élites latinoamericanas basadas en la cultura de la renta adoptaban hábitos de consumo de bienes suntuarios imitando a las élites europeas, haciendo esfuerzos conscientes por desligarse de las tradiciones locales. Símbolo de este proceso fue la ópera italiana de Manaos, en el corazón del Amazonas brasilero, inaugurada en 1896 durante la fiebre del caucho (Filho, 2010).

Durante los tres primeros siglos de su historia, Chile estuvo protegido de la cultura de la renta; el clima mediterráneo la preservó del modelo de plantación, propio de las zonas tropicales. Y las escasas tierras cultivables, necesitadas de costosas obras de riego, protegieron a Chile de la cultura de la renta agropecuaria. La cultura del trabajo se mantuvo vigente en Chile. Sin embargo, a fines del siglo XIX esta situación cambió. Después de la guerra del Pacífico, con la anexión de los recursos de Atacama y Tarapacá, las élites chilenas cedieron a la cultura de la renta y el consumo suntuario. $\mathrm{Si}$ en Brasil los capitanes de la industria del caucho contrataban compañías internacionales de ópera en Manaos, las elites chilenas hicieron lo propio con otras figuras reconocidas en Europa. El caso emblemático fue la presentación de la actriz Sara Bernhardt en Iquique, en 1886, durante el auge del salitre (González, 2013).

Paralelamente, el éxito militar creó un ambiente triunfalista en las élites chilenas que se vieron arrastradas hacia un consumismo europeizante. $\mathrm{La}$ victoria no se celebró con asoleado, hasta entonces el rey de los vinos nacionales, sino con champagne (Del Solar, 1910; Couyoumdjian, 2006). Y a partir de entonces las élites chilenas consolidaron la costumbre de brindar con espumante europeo, mientras que el jerez se consolidaba como el aperitivo de los salones, y el oporto era el bajativo. Como resultado, el vino asoleado de Concepción y Cauquenes se quedó sin mercado. Sus altos costos y elevados precios lo dejaban fuera del alcance de los sectores populares. Por tanto, ante la deserción de las élites, el vino emblemático de la viticultura nacional comenzó a declinar, en un movimiento paralelo al que sufrió el queso de Chanco y otros productos de alta calidad que hasta entonces había consumido la élite chilena. 
El ambiente cultural e ideológico dentro del cual se produjo este cambio estuvo signado por la sobrevaloración de los modelos vitivinícolas europeos y el desprecio por los productos criollos, nacidos de la tradición local durante los tres siglos de la época española. En el marco del apogeo de las Grandes Potencias de la segunda mitad del siglo XIX, Francia e Inglaterra, las élites chilenas -como en el resto de América Latina- estaban seducidas y encandiladas por el prestigio de esas naciones. Un proceso que se ha llamado de "intoxicación identitaria" y "colonialismo consumista" (Jeffs, 2014; Lacoste et al, 2014).

Otro problema fueron las imitaciones del Asoleado de Cauquenes y Concepción, dentro de Chile. Productores de otras regiones del país trataron de apropiarse de la fama y prestigio del producto, construido con el sacrificio y esfuerzo de sus comunidades. Se comenzaron a elaborar productos copiados del original, pero en otras zonas, tanto en el Norte Chico como en el centro del país. El mercado se saturó de "vinos asoleados" de diferentes procedencias, lo que contribuyó a debilitar las posibilidades de los productos originales.

\section{Vinos asoleados en el INAPI: batallas por la imagen (1920-1950)}

La evolución de las etiquetas del vinos asoleados del Norte Chile se puede conocer en los registros del Instituto Nacional de la Propiedad Industrial (INAPI). Entre las décadas de 1920 y 1950 se presentaron varias propuestas para comercializar estos productos dentro del mercado chileno. Estas etiquetas muestran las batallas culturales, económicas y políticas que se libraron en el terreno, y se reflejaron en el desarrollo y las representaciones de los asoleados.

El prestigio de este producto contribuyó a posicionarlo en los mercados, ello despertó la codicia de otros comerciantes que trataron de lucrar con el esfuerzo ajeno. Concretamente, en la zona central de Chile, sobre todo en Santiago, surgieron empresas dispuestas a comercializar sus productos, apelando al prestigio del concepto de "Asoleado". Así quedó documentado en los registros del INAPI, donde se recibieron solicitudes para comercializar "Asoleado" hecho fuera de la zona de origen. Así, por ejemplo, en 1932 se registró el "Asoleado Santa Familia", con sede en Santiago (Figura 8).

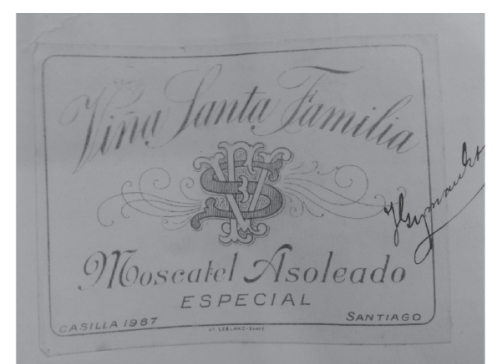

Figura 5. Etiqueta de Vino Asoleado, marca "Viña Santa Familia", Santiago de Chile, registrada por José Spriano M. Fuente: INAPI, solicitud 1948, orden 49096.

Más audaz fue el caso de Juan Mitjans, agresivo comerciante de Santiago, especializado en comercializar productos con nombres famosos de Europa, como oporto, jerez y champagne, entre otros. En este caso, su estrategia fue utilizar también la fama del asoleado. En efecto, en 1922, el INAPI aceptó la solicitud de registro formulada por un comerciante asentado en Santiago, Juan Mitjans. El marbete plantea dos irregularidades en forma simultánea. En primer lugar, reivindica el nombre de "Asoleado" para un producto que no proviene de la zona productora legítima. Segundo, lo mezcla con otro producto típico famoso, de origen europeo: "Jerez". Con clara intensión de engañar al consumidor, el comerciante se propone aprovechar la fama de estos dos productos en beneficio propio (Figura 6). ${ }^{11}$

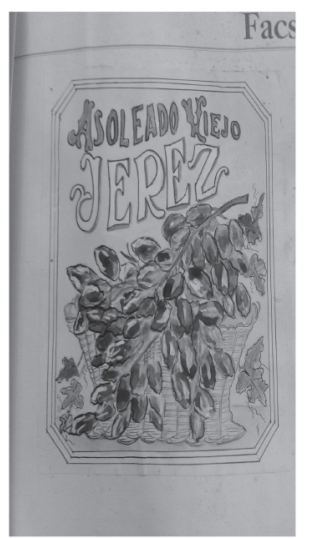

Figura 6. Etiqueta de vino asoleado registrada por Juan Mitjans, 16 de noviembre de 1922. Fuente: Archivo del Instituto Nacional de Propiedad Industrial (INAPI). Registro 28716.

Resulta difícil ponderar el impacto de los comerciantes de Santiago, que usaron la fama del vino asoleado para lucrar con sus productos de dudosa calidad, en desmedro del prestigio de 
productos elaborados con tanto esfuerzo. Al entregar al mercado bebidas manipuladas, y a fuerza de engañar al consumidor acerca de la naturaleza del producto comercializado, estos grupos dañaron gravemente el prestigio del asoleado.

En el Norte Chico de Chile también surgieron iniciativas interesadas en reivindicar la fama del asoleado para sus proyectos comerciales. Dentro de los marbetes conservados en este archivo, particular interés tiene el llamado "Vendimiadora del Asoleado". Se trata de una singular etiqueta que, a la vez, valora el paisaje vitivinícola del Norte Chico y el protagonismo de la mujer trabajadora. Al parecer, esta propuesta tuvo éxito comercial, pues se mantuvo vigente durante varios años. Fue registrada por primera vez en 1930, y renovada en $1948 .{ }^{12} \mathrm{El}$ diseño es igual; la única diferencia es el tono del color amarillo del marbete (tenue en 1930 más intenso en 1948).

La "Vendimiadora del Asoleado" es una etiqueta formada por dos partes: el marbete principal, con formato cuadrangular, y el medallón ilustrado, ovalado, en la parte superior-central de la etiqueta. El marbete entrega la información de marca ("Lágrima Cristi"), tipo de producto ("Asoleado") y origen geográfico ("Huasco"). La ilustración es suave, con aspecto de guarda, formada por sarmientos, zarzillos y hojas de parra. El diseño ilustrativo más importante se encuentra en el medallón ovalado, que cuenta con tres planos: $1^{\mathrm{er}}$ plano: vendimiadora, cepa y barricas; $2^{\circ}$ plano: viñedos en lontananza; $3^{\text {er }}$ plano (telón de fondo): montañas. La vendimiadora tiene sombrero y trenzas; usa vestido de mangas cortas y cuello cerrado, con lunares rojos; cinturón y pañuelo al cuello, también rojos. La vendimiadora estruja un racimo de uva y las gotas caen en un vaso.

La identidad regional, como base de la imagen del asoleado del Norte Chico chileno, fue el concepto central del "Lágrima Cristi", y en otros productos, como el asoleado de Paihuano. Este fue registrado por Enrique Rojas Araya en 1948. ${ }^{13}$ Además de mencionarse el producto típico "vino asoleado", la identidad regional e histórica se representa con la ilustración de dos personas que brindan con sendas copas: un conquistador español y un huaso chileno.

Los viticultores del Norte Chico de Chile reivindicaron el Asoleado como producto típico de la región, tratando de competir con la fama obtenida por este producto en Cauquenes y Concepción.

En el centro del valle Central también se detectaron iniciativas tendientes a promover el

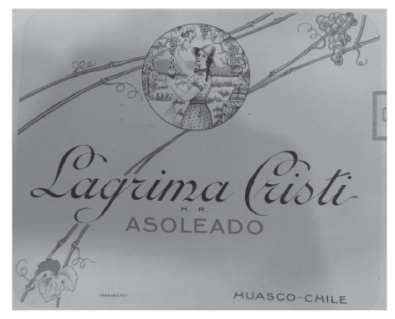

Figura 7. Asoleado "Lágrima Cristi” (1930).

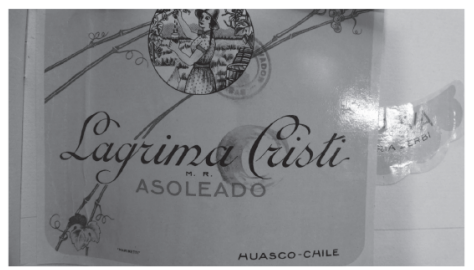

Figura 8. Asoleado "Lágrima Cristi” (1948).

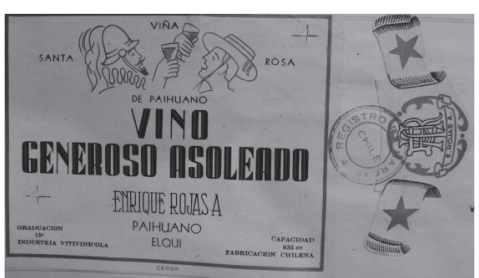

Figura 9. Vino generoso asoleado de Viña Santa Rosa, Paihuano, valle del Elqui (1948).

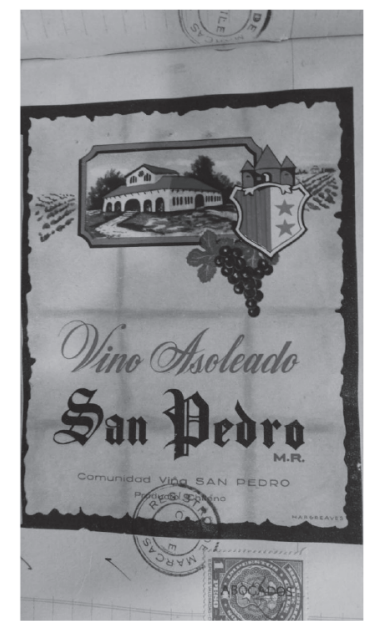

Figura 10. Etiqueta de vino asoleado, registrada por la Viña San Pedro el 6 de enero de 1949. Fuente: Archivo del Instituto Nacional de Propiedad Industrial (INAPI). Registro 87469.

asoleado como producto atractivo a nivel comercial. La poderosa viña San Pedro, con sede en Curicó, también participó de esta tendencia. Así lo reflejó en el registro solicitado al INAPI en 1949 (Figura 10). 
Los registros del INAPI muestran la notable dispersión del uso del concepto "Asoleado" en el mercado chileno en el segundo cuarto del siglo XX. Diversas empresas comerciales se apropiaron de este concepto para lucrar con su fama y prestigio. La ausencia de reglamentos y leyes que protegieran los derechos de la comunidad que construyó y sostuvo el prestigio del asoleado, facilitó este proceso que generó el debilitamiento de su identidad y calidad.

La acción del Estado, en defensa del asoleado como producto típico de la zona sur del Maule, llegó recién hacia 1954 cuando el mismo fue delimitado como Denominación de Origen. De todos modos, ya era tarde. Para entonces, la fama del asoleado ya se había perdido en los mercados chilenos.

\section{Conclusión}

El presente artículo ha permitido reconstruir los principales jalones en el camino histórico del vino asoleado de Cauquenes y Concepción, en la segunda mitad del siglo XIX, etapa clave en su historia por marcar su apogeo y decadencia.

El vino asoleado surgió en el secano interior al sur del Maule, entre Cauquenes y Concepción. Fue elaborado principalmente por pequeños campesinos pobres signados por la escasez de capital y la austeridad de sus recursos, en un contexto de precarias condiciones de transporte previo al ferrocarril. En estas condiciones, el flete representaba un porcentaje importante del precio final del producto. Para bajar el costo relativo del flete, los pequeños viticultores del secano costero e interior idearon la forma de obtener un producto de mayor valor, y obtuvieron el vino asoleado. Este no requería mayor capital, sino mayor trabajo. Hermano del queso de Chanco, el vino asoleado de Cauquenes y Concepción era resultado de la cultura del trabajo de los campesinos pobres del sur del valle Central de Chile.

El esfuerzo de los viticultores de Cauquenes y Concepción para elaborar un vino de mayor calidad fue valorado por los mercados de Santiago y otras ciudades chilenas. Las élites nacionales estuvieron dispuestas a pagar un precio mayor por un producto mejor, con su debida identificación geográfica como señal de calidad y prestigio. Con el tiempo, el concepto de vino asoleado de Cauquenes, y en menor medida, asoleado de Concepción, se convirtieron en productos famosos y de alto precio. En las décadas de 1850, 1860 y 1870 los comerciantes de Santiago, Valparaíso, La Serena, Chillán y otras ciudades chilenas, se apoyaron en el asoleado de Cauquenes y Concepción para desarrollar sus campañas comerciales en los medios de prensa. Fue la era dorada del asoleado. Las tiendas de licores, los almacenes y comercios dedicados a alimentos y bebidas utilizaban el asoleado como producto estrella para atraer clientes. Alrededor de este producto se diseñaron ingeniosas campañas publicitarias, vinculando el asoleado con símbolos de estatus y prestigio de nivel nacional a internacional. Un símbolo de esta tendencia fue la publicidad que catalogaba al asoleado como un regalo digno de ofrecerse a Garibaldi, héroe nacional en Uruguay, Argentina e Italia, personaje reconocido por el escritor más famoso del momento, Alejandro Dumas. Nótese que el aviso se publicó en Santiago el 15 de setiembre de 1860 , pocos días después del ingreso triunfal de Garibaldi a Nápoles.

En vísperas de la guerra del Pacífico, las condiciones parecían dadas para la consolidación del asoleado como el primer vino chileno con Denominación de Origen, para ocupar dentro de su país el sitio que tenían el oporto en Portugal, el jerez en España y el champagne en Francia: había un producto de buena calidad, que llegaba en buenos medios de transporte a los mercados, y contaba con buenos canales de distribución, promoción y comercialización. Era el rey de los vinos chilenos y ocupaba un lugar central en la valoración de las élites. El mercado sabía ponderar sus cualidades y estaba dispuesto a pagar un precio mayor por el asoleado.

De todos modos, la guerra del Pacífico no sirvió para consolidar al asoleado, sino al contrario. Todas las expectativas respecto de su desarrollo se vieron frustradas. En lugar de valorar su identidad y sus productos típicos, después de la victoria militar, la élite tomó distancia de sus propios elementos. Simbólicamente fue muy violenta la celebración del triunfo con champagne francés: a partir de allí se abrió una nueva etapa signada por la inclinación de las élites chilenas a consumir productos importados sustitutivos (jerez, champagne, oporto) y abandonar el asoleado a su suerte. Esta tendencia se vio favorecida por los nuevos ingresos fiscales que Chile comenzó a tener a partir de la anexión de las riquezas de la guerra, lo que anuló el papel regulador de los aranceles de importación.

En cierta forma, las salitreras del desierto de Atacama fueron un caballo de Troya para el desarrollo de productos agroalimentarios de alta calidad, como el vino asoleado de Cauquenes y 
Concepción y el queso de Chanco, entre otros. A cambio de materias primas de fácil explotación, Chile perdió productos con alto valor agregado, que habían costado un siglo construir.

\section{Agradecimientos}

Los autores agradecen al Proyecto Fondecyt 1130096.

\section{Literatura Citada}

\section{Álvarez E., C.P.}

2001. Derecho del vino. Denominaciones de Origen. Santiago, Editorial Jurídica de Chile. 150 p.

Briones, F.

2006. Los inmigrantes franceses y la viticultura en Chile: el caso de René F. Le Feuvre. Universum 21 (2): 126-137.

Buitrago, A.

2014. La vitivinicultura emergente en Bolivia y las oportunidades para el Singani. Rivar, 1 (2): 87-101.

Castro, A.

2014. Curar penas, alegrar el alma. Alcohol y vino en los relatos campesinos chilenos. Rivar, 1 (1): 60-77.

Coello, C.

2008. El Sistema Jurídico de las Denominaciones de Origen.

Las Bases Históricas y Administrativas del Derecho Vitivinícola Español. Sevilla, Junta de Andalucía, Instituto Andaluz de Administración Pública. Conserjería de Justicia y Administración Pública. Sevilla. España. 1460 pp.

Cortés, H.

2005. El origen, producción y comercio del pisco chileno, 1546-1931. Universum, 20 (2): 42-81.

Couyoumdjian, J.R.

2006. Vinos en Chile desde la independencia hasta el fin de la Belle Époque. Historia 39 (1): 23-64.

Del Pozo, J.

2014. Historia del vino chileno. Desde la época colonial hasta hoy. LOM Ediciones. Santiago, Chile. 316 p.

Del Solar, A.

1910. Diario de Campaña. Santiago, 1885. 2 edición: Santiago, $117 \mathrm{p}$.

Duhart, F.

2011. Reflexiones desde la ecoantropología sobre el terroir. Mundo Agrario, 11 (22): 1-17.

Dumas, A.

2005. La Nueva Troya. La guerra privada de Dumas contra Rosas. Buenos Aires, Marea Editorial. 160 p.

Errázuriz Tortorelli, C.

2010. Indicaciones geográficas y denominaciones de origen: propiedad intelectual en progreso. Revista chilena de derecho, 37 (2): 207-239.

Filho, Fadel. D.A.

2010. Riqueza e miseria do ciclo da borracha na Amazônia brasileira: um olhar geográfico por intermèdio de Euclides da Cunha. En: Texeira de Godoy, P. História do pensamento geográfico e epistemologia em Geografia. São Paulo: Editora UNESP, 2010. Pp. 187-208.

Gay, C.

1855. Historia física y política de Chile. Tomo II: Agricultura. Santiago, Museo de Historia Natural. Edición moderna consultada: Santiago, Icira, 1973.
González, S.

2013. La Sociedad del Salitre. Protagonistas, migraciones, cultura urbana y espacios públicos. Santiago, RIL editores, 2013. 554 p.

Huertas, L.

2012. Cronología de la producción del vino y del Pisco (Perú 1548-2010). Lima: Editorial Universitaria. Lima, Perú. $391 \mathrm{pp}$.

Jeffs, J.G.

2014. Coñac, Pisco, Jerez y Oporto: batallas comerciales a través de la prensa chilena (1870-1885)". Rivar, 1 (1): 75-85.

Jiménez, D.

2014. La consolidación de la Denominación de Origen Pisco (1931): una mirada desde los debates parlamentarios y sus referentes internacionales (1901-1931). Rivar, 1 (2): 71-86.

Lacoste, P.; Soto, N.; Jiménez, D.

2014. Genesis and identity of Chanco cheese (Chile 17501860) Contribution to thestudy of Appellations of Origin in Latin America. Ciencia e Investigación Agraria. Revista Latinoamericana en Ciencias de la Agricultura y Ambientales, 41 (3): 317-325.

Lacoste, P.; Jiménez Cabrera, D.I.; Briones Quiroz, F.M.; Castro

San Carlos, A.; Rendón Zapata, B.M.; Jeffs Munizaga, J.G.

2014. Burdeos de Talca y Champagne de Mendoza: Denominaciones de Origen y contaminación identitaria de vinos en Argentina y Chile. Mundo Agrario, 15 (29). ISSN 1515-5994.

Lacoste, P.; Jiménez, D.; Castro, A.; Rendón, B.; Soto, N. 2013. A binational Appellation of Origin: Pisco in Chile and Peru. ChileanJournal of AgriculturalResearch 73(4): 107-114.

Lacoste, P.; Aranda, M.; Matamala, J.; Premat, E.; Quinteros,

K.; Soto, N.; Gaete, J.; Rivas, J.; Solar, M.

2011. Pisada de la uva y lagar tradicional en Chile y Argentina (1550-1850). Atenea, 502: 39-81.

Le Feuvre, R.F.

1890. Informe pasado al señor Ministro de Industria y Obras Públicas sobre el estado actual de la agricultura y muy especialmente de la viticultura en la provincia de Maule y los medios de fomentar estas industrias. Boletín de la Sociedad Nacional de Agricultura, vol. XXI, 20 de julio de 1890.

Málaga, A.

2014. La ruta del vino y del pisco en el valle de Vítor (Arequipa). Turismo y Patrimonio, 8: 133-156.

Mayorga, M.

2014. La tradición de la producción artesanal de aguardiente en Cauquenes, 1771-1821. Rivar, 1(2): 55-70.

Molina Núñez, J.; Araya, J.A.

1917. Selva lírica. Estudio sobre los poetas chilenos. Santiago, Chile. Universo. 468 p. 
Pérez Rosales, V.

1886. Recuerdos del pasado 1814-1860. Imprenta Gutenberg, Santiago, Chile.

Pszczólkowski, P.

2014. "Terroir" y "Climats": ¿realidad o quimera? Rivar, 1 (1): 13-19.

Pszczólkowski, P.

2015. SauvignonBlanc, Cabernet-Sauvignon y Carmenère, cepas claves de la viticultura actual de Chile. Rivar, 2 (4) (Santiago, enero 2015): 1-20.

Rojas, M.

1950. Tratado de Viticultura y Vinificación. 1 edición: Talca, La Libertad, 1981. $5^{\circ}$ edición refundida: Santiago, Editorial Nascimento. 667 p.
Sánchez Andaur, R.

2006. Viticultores jesuitas en el obispado de Concepción (Chile). Universum, 21 (1):92-103.

Stewart, D.

2015. Las viñas de Concepción: distribución, tamaño y comercialización de su producción durante el siglo XVII. Rivar, 2(4): 106-124.

Soto, N.

2015. El paisaje del vino en Cauquenes (1700-1850). Rivar, $2(4)$ :

Troyat, $\mathrm{H}$.

2006. Alejandro Dumas. El quinto mosquetero. Buenos Aires, Editorial El Ateneo. 463 p.

Valladares Campos, J.

1979. La hacienda Longaví, 1639-1959. Historia, 14:103-205.

\section{Notas}

1 Acuerdo del Cabildo de Talca, 16 de octubre de 1764. Archivo Nacional de Santiago de Chile (AN), Actas de Cabildo de Talca (ACT), pág. 64.

2 AN, ACT, 16 de octubre de 1764 pág. 64.

AN, ACT, 24 de julio de 1775 pág. 91.

AN, ACT, 28 de junio de 1775 pp. 89-90.

AN, ACT, 28 de junio de 1775, pág. 89.

AN, ACT, 16 de octubre, foja 64.

7 Acuerdo Mutuo, Cauquenes, 12 de setiembre de 1865. AN, Fondo Notariales de Cauquenes, volumen 78, fojas $313 \mathrm{v}-314 \mathrm{v}$.

8 El Mercurio, 21 de julio de 1879.

9 El Mercurio, 3 de agosto de 1872.

10 "Vino asoleado, rico de primera calidad de la Hacienda de San Nicolás de Longavî". El Mercurio, 27 de enero de 1872.
11 INAPI, Registros de Marcas No 28716; 16 de noviembre de 1922, Juan Mitjans, domiciliado en Santiago. Vinos y licores, clase 69. Texto del marbete: "Asoleado Viejo Jerez". Dibujo: recimo de uvas deshidratadas sobre canasta de mimbre.

12 INAPI Registro 46098, 23 de junio de 1930. Juan M Zevega. Asoleado "Lágrima Cristi”, Huasco. INAPI Registro de marca número $\mathrm{N}^{\circ} 3306 \mathrm{~A} / 75740$ (55333). 15 de mayo de 1945. Guillermo Zerbi. Asoleado "Lágrima Cristi”, Huasco.

13 INAPI, Registros de Marcas N ${ }^{\circ} 21855^{\mathrm{a}} / 85701 ; 13$ de julio de 1948, Enrique Rojas Araya, comerciante, domiciliado en Paihuano, Elqui. Vinos y licores, clase 69. Texto del marbete: "Vino Generoso Asoleado" Viña Santa Rosa de Paihuano. Enrique Rojas -Paihuano- Elqui. Graduación: 15; Capacidad: $625 \mathrm{~cm} 3$. Collarín: EAR. (¿Anticipo de las RRR?). Dibujo: perfil de un conquistador español y perfil de un huaso chileno, brindando con copas. 
